\title{
Trypanosoma caninum, a New Parasite Described in Dogs in Brazil: Aspects of Natural Infection
}

\author{
Author(s): Maria F. Madeira, Arleana B. P. F. Almeida, Juliana H. S. Barros, Tatiana S. F. Oliveira, \\ Valeria R. F. Sousa, Andreia S. Alves, Luciana F. C. Miranda, Armando O. Schubach, and Mauro C. A. \\ Marzochi \\ Source: Journal of Parasitology, 100(2):231-234. \\ Published By: American Society of Parasitologists \\ DOI: http://dx.doi.org/10.1645/13-297.1 \\ URL: http://www.bioone.org/doi/full/10.1645/13-297.1
}

BioOne (www.bioone.org) is a nonprofit, online aggregation of core research in the biological, ecological, and environmental sciences. BioOne provides a sustainable online platform for over 170 journals and books published by nonprofit societies, associations, museums, institutions, and presses.

Your use of this PDF, the BioOne Web site, and all posted and associated content indicates your acceptance of BioOne's Terms of Use, available at www.bioone.org/page/terms_of_use.

Usage of BioOne content is strictly limited to personal, educational, and non-commercial use. Commercial inquiries or rights and permissions requests should be directed to the individual publisher as copyright holder. 


\title{
TRYPANOSOMA CANINUM, A NEW PARASITE DESCRIBED IN DOGS IN BRAZIL: ASPECTS OF NATURAL INFECTION
}

\author{
Maria F. Madeira, Arleana B. P. F. Almeida, Juliana H. S. Barros, Tatiana S. F. Oliveira, Valeria R. F. Sousa, Andreia S. Alves,
} Luciana F. C. Miranda, Armando O. Schubach, and Mauro C. A. Marzochi

Laboratório de Vigilância em Leishmanioses, Instituto de Pesquisa Clínica Evandro Chagas, Fundação Oswaldo Cruz, Av. Brasil 4365, Rio de Janeiro 21045900. Correspondence should be sent to: fatima.madeira@ipec.fiocruz.br

\begin{abstract}
Trypanosoma caninum constitutes the most recent trypanosomatid species infecting dogs in Brazil. Due to the limited data available about this parasite, this study aims to disclose clinical and laboratory findings from 14 dogs naturally infected. The dogs were diagnosed during a cross-sectional survey in Cuiabá (Mato Grosso, Brazil) and followed up at an interval of 3, 6, and 12 mo in order to evaluate the clinical evolution and to investigate the parasite, the DNA, or both in different biological samples (intact skin, cutaneous scar, blood, bone marrow, and lymph node aspirate) by parasitological (culture and smear exam) and molecular (DNAbased tests) methods. Specific anti-T. caninum and anti-Leishmania antibody production was also evaluated. Ten of 14 dogs infected by $T$. caninum showed a good general state at the time of diagnosis, and this status did not vary during the follow-up. Anti-T. caninum and anti-Leishmania IgG antibodies were detected by IFAT in 10 and 2 animals, respectively. Concomitant infection by Leishmania chagasi was confirmed in $2 \mathrm{dogs}$, indicating an overlap of endemic areas in Cuiabá. Trypanosoma caninum (parasite or DNA) was found only in the intact skin in all animals examined. Our results suggest that $T$. caninum infection can be manifested as an asymptomatic case with low humoral immune response.
\end{abstract}

Trypanosoma caninum was initially described in the state of Rio de Janeiro (Madeira et al., 2009; Pinto et al., 2010) and later in other states in Brazil. Although it is only a recently identified species, 53 cases of natural infection in dogs were already reported in areas where canine visceral leishmaniasis (CanL) is endemic (Barros et al., 2012). Data related to the pathogenesis of this parasite in $\operatorname{dogs}$ and the epidemiological aspects are still unknown. Trypanosoma caninum is isolated exclusively from intact skin fragments, an unusual feature of the Trypanosoma genus; it also does not infect triatomine insects and it grows very well in axenic cultures, with a predominance of epimastigote forms (Madeira et al., 2009). Molecular analyses of partial SSU ribosomal DNA sequences have shown that all isolates from $T$. caninum described so far are genetically identical or closely similar (Barros et al., 2012). Apparently, this parasite is not very immunogenic for dogs, even though it is able to stimulate the production of specific antibodies (Alves et al., 2012).

Visceral leishmaniasis (VL) is endemic in many Brazilian regions, and the dog is the main domestic reservoir, playing an important role in the epidemiological cycle, and is considered to be an important target in the control of this parasite (Ministerio da Saúde, 2006). The phenomenon of T. caninum parasitizing domestic dogs in overlapping areas with VL is an important consideration, mainly for its potential impact on the VL control strategies that are being implemented in Brazil.

The acquisition of 14 dogs naturally infected by $T$. caninum allowed a rare opportunity for clinical and laboratory study of this disease.

\section{MATERIALS AND METHODS}

\section{Animals and collection of biological samples}

Fourteen dogs naturally infected by $T$. caninum were studied. The animals were identified during the cross-sectional survey for CanL conducted in Cuiabá city, Mato Grosso, in 2009 (Almeida et al., 2011). Infection was diagnosed by parasite isolation and posterior identification by PCR (18S rDNA), followed by amplicon sequencing for which results

Received 14 May 2013; revised 30 November 2013; accepted 11 December 2013.

DOI: $10.1645 / 13-297.1$ have already been deposited in GenBank (Barros et al., 2012). For the physical examination and collection of biological samples, the animals were sedated with ketamine associated with acepromazine, as approved by the Ethics Committee on the Use of Animals, Oswaldo Cruz Foundation (CEUA, license number LW-01/10). The physical examination was based on clinical signs compatible with CanL (e.g., weight loss, lymphadenopathy, conjunctivitis, alopecia, splenomegaly, and presence of ulcers or cutaneous scars). Then the following biological samples were collected: (1) Blood: obtained from the jugular vein with syringe and placed into 2 tubes, one for obtaining serum for the serological tests and the other containing anticoagulant (EDTA) for culture and molecular assays. Also, part of this material was smeared onto slides for cytological exam. (2) Bone marrow: about $0.5-1.0 \mathrm{ml}$ were collected from the sternum and placed into a tube containing EDTA and processed in the same way as the blood. Slides with bone marrow smears were also prepared. (3) Lymph node: this material was obtained by puncture of the most-enlarged popliteal lymph node with a Valery aspirator. Two slides with smears were prepared with the punctured material and the remainder were used for molecular analysis. (4) Tissue fragments: intact skin fragments were collected from the scapular region after trichotomy, antisepsis, and local anesthesia with lidocaine $2 \%$. Two fragments were placed in physiological solution for culture and 1 fragment was stored at $-20 \mathrm{C}$ for molecular tests. Cutaneous scar fragments were processed in the same way as the skin.

The animals were followed up at intervals of 3, 6, and 12 mo after the initial diagnosis in order to evaluate the clinical evolution of the infection by $T$. caninum and investigate the parasite or the DNA in different biological samples by parasitological and molecular tools.

\section{Serological tests}

Anti-T. caninum and anti-Leishmania sp. IgG antibodies were assessed in serum of all the animals by indirect fluorescence antibody test (IFAT), immunoenzymatic assay (an ELISA), and an immunochromatographic test DPP ${ }^{\circledR}$ (Dual Path Platform).

Anti- $T$. caninum $\operatorname{IgG}$ antibodies were researched using in-house tests (IFAT and ELISA) with homologue antigens following protocols already standardized by our group (Alves et al., 2012). For the tests to detect antiLeishmania IgG antibodies, IFAT (IFI-leishmaniose visceral canina), ELISA (EIE-leishmaniose visceral canina), and the rapid immunochromatographic test $\left(\mathrm{DPP}{ }^{\circledR}\right)$ kits were used. These commercial tests are manufactured by Bio-Manguinhos/FIOCRUZ/MS and distributed to public service offices for CanL diagnosis in Brazil (Ministério da Saúde, 2006). The kits were used following the manufacturer's instructions.

\section{Culture procedure and smear examination}

The culture of intact skin and scar fragments, blood, and bone marrow was done according to the following steps. Tissue fragments were initially immersed in saline solutions containing 1,000 U penicillin, $200 \mu \mathrm{g}$ 
streptomycin, and $50 \mu \mathrm{g} 5^{\prime}$ fluorocytosine per milliliter and stored at $4 \mathrm{C}$ for $24 \mathrm{hr}$. Thereafter, each fragment was seeded into screw-cap tubes containing blood-agar slants (NNN-Novy, MacNeal, and Nicolle) overlaid with $1.5 \mathrm{ml}$ of Schneider's Drosophila medium supplemented with $10 \%$ fetal calf serum. The blood and bone marrow (about $0.2-0.3 \mathrm{ml}$ ) were seeded immediately after the collection in tubes containing the same culture medium. All cultures were duplicated, processed, and kept at $27 \mathrm{C}$ $( \pm 0.4 \mathrm{C})$ and examined weekly under optical microscopy for 40-50 days. The isolated parasites were identified by PCR assay (epimastigote forms) or by an isoenzyme electrophoresis technique (promastigote forms) as previously described (Almeida et al., 2011; Barros et al., 2012).

The smears of blood, bone marrow, and lymph node aspirates were fixed in methyl alcohol and later stained by Giemsa. The slides were examined through optical microscopy scanning at least 2,000 microscopic fields $(\times 1,000)$ looking for the presence of parasites.

\section{Molecular assays}

The blood, bone marrow, and tissue (intact skin and scar fragments) samples were processed by 3 different PCR assays. Initially, the DNA of all samples was extracted in accordance with the phenol-chloroform method (Gomes et al., 2007). After this procedure the DNA was stored at $-20 \mathrm{C}$ until PCR assays.

DNA detection with targets directed to $18 S$ gene ( $r D N A)$ : The nestedPCR protocol was used (Smith et al., 2008), and this same approach had been used to identify all $T$. caninum isolates until then. External primers TRY927F (5'-GAAACAAGAAACACGGGAG-3') and TRY927R (5'CTACTGGGCAGCTTGGA-3') were applied for the first round and internal primers SSU561F (5'-TGGGATAACAAAGGAGCA-3') and SSU561R (5'-CTGAGACTGTAACCTCAAAGC-3') were applied for the second round. Each PCR run included T. caninum DNA (MCAN/BR/ 2003/A27) and L. chagasi DNA (MHOM/BR/1974/PP75) as positive controls.

$D N A$ detection with targets directed to $k D N A$-minicircle: This followed a protocol previously described using the primers $5^{\prime}-(\mathrm{G} / \mathrm{C})(\mathrm{G} / \mathrm{C})(\mathrm{C} / \mathrm{G})$ CC(A/C)CTAT(A/T)TTACACAACCCC-3' and 5'-GGGGAGGGGCGTTCTGCGAA-3' (Degrave et al., 1994). Leishmania chagasi DNA was used as a positive control.

$D N A$ detection of the $\beta$-globin gene: This assay was used as an internal control of PCR reactions in order to confirm the absence of inhibitors in the samples. The primers 5'-CAA CTT CAT CCA CGT TCA CC-3' and 5'-ACA CAA CTG TGT TCA CTA GC-3', which amplify a product of $118 \mathrm{bp}$, were used following the protocol according to Quaresma et al. (2009).

All PCR products were run on a $1.5 \%$ agarose gel, stained with ethidium bromide, and visualized under ultraviolet light.

\section{RESULTS}

Among the 14 dogs studied, 11 were male, 12 had non-defined breed, and the ages ranged between 8 mo and $8 \mathrm{yr}$ (median $=2 \mathrm{yr}$ ). The follow-up was carried out at 3, 6, and 12 mo after the $T$. caninum infection diagnosis in 8,3 , and 1 dogs, respectively. The other dogs could not be found or were taken to other regions. At the moment of the initial diagnosis, 10 dogs were in good general state and 4 showed 1 or 2 clinical signs such as weight loss $(n=2)$, lymphadenomegaly (1), and splenomegaly (2). One animal (no. 799) displayed a cutaneous scar on the scrotum. Only 1 dog (no. 732) had its clinical status changed at 6 mo after it developed lymphadenopathy, splenomegaly, conjunctivitis, and hair loss, compatible with the clinical signs of CanL, and infection by $L$. chagasi was later confirmed by culture methods and isoenzyme electrophoresis.

Anti- $T$. caninum antibodies were detected in 10 animals by IFAT, with titers varying from 1:40 to $1: 640$, and in 8 animals by ELISA. Employing the specific kits for CanL diagnosis, 2 animals (732 and 799) were positive to IFAT, with titers of 1:40 and 1:80, respectively. All animals were negative in EIE and only animal no. 732 showed a positive result in DPP.
Trypanosoma caninum infection was established through culture of skin fragments. By this technique, cutaneous scar (only dog 799), blood, and bone marrow collected at the same time were negative for the presence of this parasite in all cases. Three months later, $T$. caninum was re-isolated from skin fragments of all the 8 dogs reexamined. The attempt to re-isolate $T$. caninum from the skin in $6 \mathrm{mo}$ ( 3 cases) and $12 \mathrm{mo}$ ( 1 case) did not succeed. Blood and bone marrow samples collected for culture at 3, 6, and 12 mo were negative in 3, 3, and 1 animal, respectively, except in 1 dog (732) in which L. chagasi was isolated from bone marrow at 6 mo.

The smear examinations of the blood, bone marrow, and lymph node samples collected upon the occasion of initial diagnosis and during the follow-up were negative except for dog no. 732 from which amastigote forms were viewed in the bone marrow sample in the 6th mo.

The PCR assay (18S rDNA) performed with skin fragments of the 14 dogs, collected at the moment of the initial diagnosis, showed positive results with amplification products similar to $T$. caninum in 12 cases, and 2 animals showed negative results. The blood, bone marrow, and lymph node samples collected at that time were negative for $T$. caninum amplification pattern in all cases. However, by this assay 1 animal (732) showed an amplification product similar to the L. chagasi pattern in the bone marrow sample. When we performed research of Leishman$i a$-specific DNA in these samples, only the bone marrow collected from animal 732 was positive.

Of the skin fragments collected from 8 dogs after 3 mo, 4 were PCR positive for $T$. caninum (nos. 527, 798, 799, and 808), whereas the research of Leishmania DNA was negative in all 8 cases. Both $T$. caninum and Leishmania DNA were negative in blood, bone marrow, and lymph node samples of the 3 dogs examined in this interval. After 6 mo, T. caninum DNA was not detected in skin, blood, bone marrow, and lymph node samples of the 3 animals reevaluated. Nevertheless, a pattern of amplification similar to L. chagasi was detected in the bone marrow and lymph node samples of animal 732 and in the cutaneous scar and lymph node samples of animal 799. This result was later confirmed by PCR using specific primers for the Leishmania donovani complex, and the expected 800-bp product was obtained in the lymph node sample (data not shown). By PCR specific assay, Leishmania DNA was detected in these samples, and the other samples showed negative results. After 12 mo, only 1 animal (604) evaluated showed negative results for both PCR assays in all the samples analyzed.

In the PCR assay for $\beta$-globin, all samples were positive, showing an expected product of about $118 \mathrm{bp}$.

All the results can be found in detail in Table I, and the pattern of amplification of T. caninum and Leishmania by PCR assays can be observed in Figure 1.

\section{DISCUSSION}

Trypanosoma caninum is a recently described parasite, and many aspects of this agent are unknown - among them is accurate diagnosis. In all cases reported so far, $T$. caninum infection has been established from the culture of dog skin fragments; however, in all of these cases the aim was the CanL diagnosis (Madeira et al., 2009; Silva et al., 2011). Using culturing success as a diagnostic tool, a prevalence of $3.19 \%$ and $5.23 \%$ of $T$. caninum 
TABLE I. Serological, parasitological, and molecular assays performed with different biological samples obtained from dogs naturally infected by Trypanosoma caninum. Tc (Trypanosoma caninum), Lc (Leishmania chagasi), (-) negative results, (+) positive results; nd (not done).

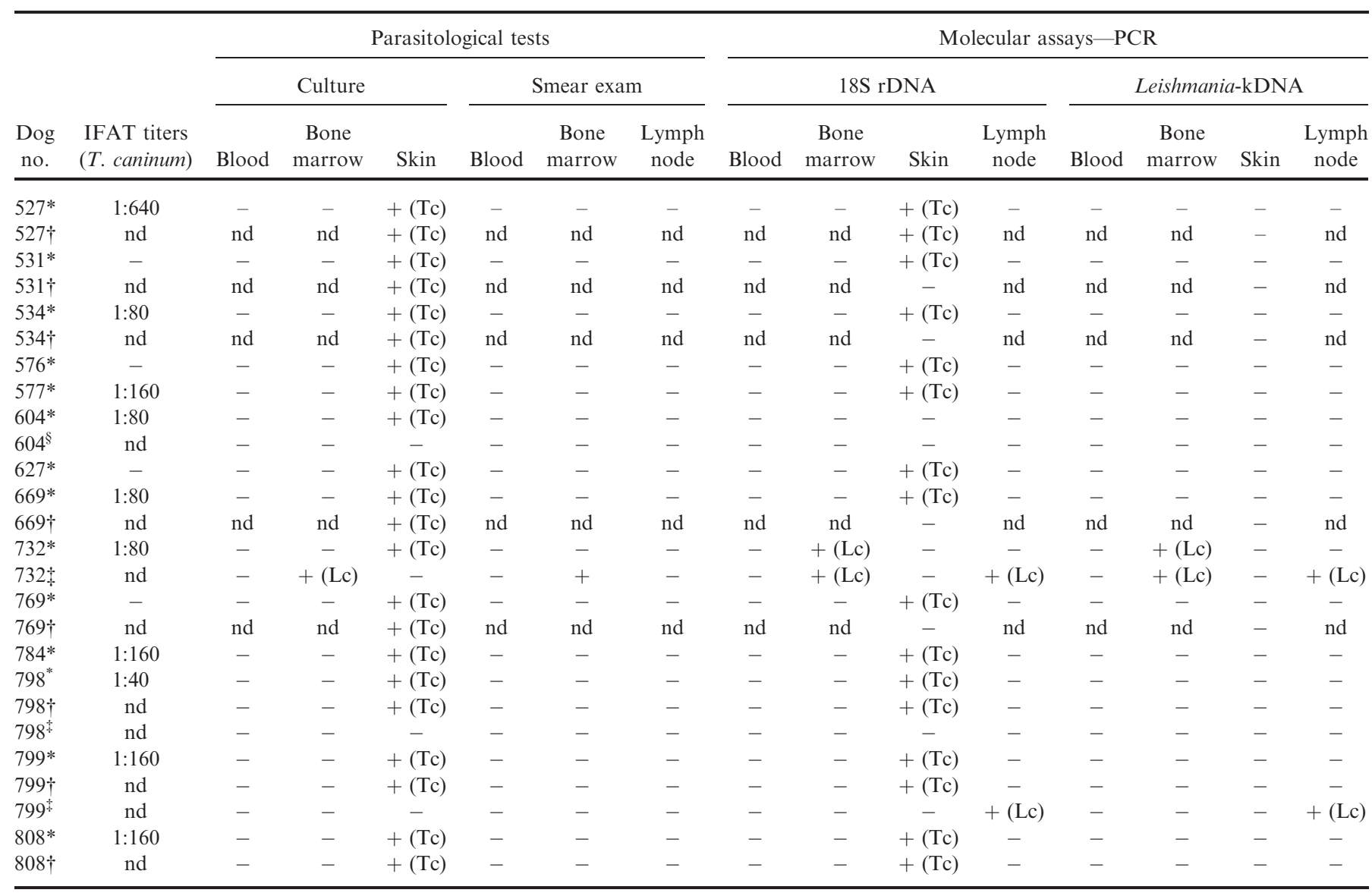

* Biological samples collected at the same occasion as the T. caninum diagnosis.

$\dagger$ After 3 mo.

* After 6 mo.

$\S$ After 12 mo.

infection has been reported (Pinto et al., 2010). Using the same test in Cuiabá city, Almeida et al. (2011) found a prevalence of $3.25 \%$. These data suggest that the prevalence of $T$. caninum may be low or that such rates are influenced by other factors. In fact, both the test and the biological sample analyzed can have an impact on the sensitivity and specificity of the diagnostic test and, consequently, on the infection prevalence rates.

Of the 14 animals studied, $71 \%$ were in good general state, even during the follow-up. Relevant clinical signs were found in only 1 animal that was co-infected by L. chagasi and then attributed to CanL. The results obtained herein, associated to previous observations, suggest that $T$. caninum infection can be asymptomatic, without specific clinical signs, and occurs with low parasitemia, making its detection difficult by the methods used up to the moment. The lack of knowledge about the biological cycle of $T$. caninum restricts the choice of biological samples to be analyzed and of more appropriate tools for its diagnosis. Considering the molecular tools applied in this study, we confirmed that this parasite is found exclusively in intact skin.

It is interesting that the first case of $T$. caninum infection was described in a dog co-infected by Leishmania braziliensis (Madeira et al., 2009), and now we report the co-infection by $T$. caninum and $L$. chagasi, demonstrating that $T$. caninum and Leishmania parasites can co-exist in concomitant infections.

Species-specific molecular targets are not available for $T$. caninum. Here, the use of targets for the region of the ribosomal gene (18S rDNA), despite being general, allowed the detection of Leishmania DNA in 2 dogs, and these results were confirmed by other tests. This approach shows that a combination of methods may be useful when the parasites are rarely studied, such as in coinfections with $T$. caninum.

The humoral immune response in the infection by $T$. caninum has been low or absent (Alves et al., 2012), and the results obtained herein corroborate this observation, showing that of 14 dogs naturally infected by this parasite $43 \%$ were seronegative, even when the homologous antigen was used in the tests. This may be related to the characteristic of $T$. caninum in which its presence appears to be limited and restricted to skin. Unlike CanL, the presence of L. chagasi in different organs and tissues is considered as 1 of the factors responsible for the high humoral immune response. The low humoral response observed in the $T$. caninum infection may on one hand limit the variety of options for its diagnosis but, on the other hand, is a positive issue considering that serology constitutes the recommendation for CanL diagnosis 


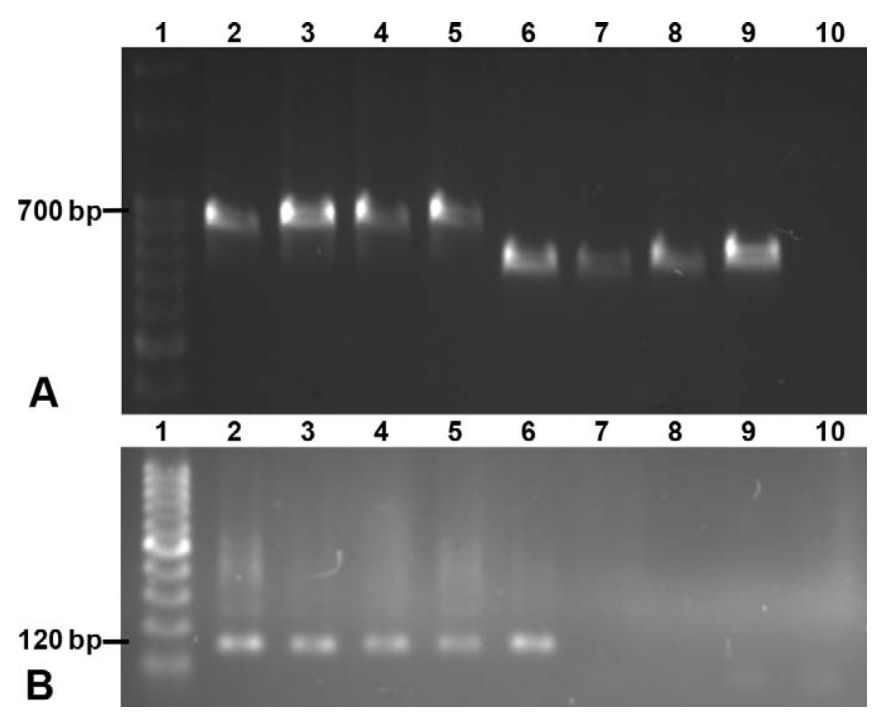

Figure 1. Agarose gel electrophoresis showing the amplified products with representative samples of the study. (A) PCR assay that targeted a partial sequence of the 18S rDNA gene. Lane 1: DNA ladder, $100 \mathrm{bp}$; Lane 2: DNA control of Trypanosoma caninum (MCAN/BR/2003/A27); Lanes 3-5 (positive samples with $T$. caninum pattern): skin of dogs 527, 531, and 534, respectively; Lanes 6-8 (positive samples with $L$. chagasi pattern): bone marrow of $\operatorname{dog} 732$, cutaneous scar of dog 799, and lymph node of dog 799, respectively; Lane 9: DNA control of Leishmania chagasi (MHOM/BR/1974/PP75); Lane 10: negative control. (B) PCR assay that the conserved region of Leishmania kDNA minicircles. Lane 1: DNA ladder, 100 bp; Lane 2: DNA control of Leishmania chagasi (MHOM/BR/ 1974/PP75); Lane 3: bone marrow sample of dog 732; Lane 4: cutaneous scar sample of dog 799; Lane 5: lymph node sample of dog 799; Lane 6: lymph node sample of dog 732; Lanes 7-9: skin of dogs 527, 531, and 534, respectively; Lane 10: negative control.

in Brazil. Among the dogs studied, only the animals co-infected by Leishmania reacted to specific tests for CanL.

The follow-up of dogs in endemic areas is a hard task. Dogs are usually taken from 1 area to another, which constitutes 1 of the reasons for the geographic expansion of some zoonoses that have the $\operatorname{dog}$ as a dispersion element; for instance with visceral leishmaniasis (Marzochi et al., 2009). Although T. caninum is apparently not pathogenic to dogs, it may represent another agent in this complicated context. Thus, it is important that the infection dynamics in this host be understood so that specific diagnostic tools can be applied.

In conclusion, this study supports a biological feature of $T$. caninum and suggests that this parasite is not pathogenic or not very virulent to dogs. Moreover, the infection course is asymptomatic and transitory with low humoral immune response.

\section{ACKNOWLEDGMENTS}

This study was funded in part by grants from PAPES VI (CNPq, process no. 407700/2012-9), Fundação de Amparo a Pesquisa do estado do Rio de Janeiro (FAPERJ, 26102321-2009), and Fundação de Amparo a Pesquisa do estado de Mato Grosso (FAPEMAT). M. C. A. Marzochi and A. Schubach are the recipients of fellowships from CNPq.

\section{LITERATURE CITED}

Almeida, A. B. F., V. R. Sousa, E. C. Boa-Sorte, F. B. Figueiredo, D. A De Paula, M. F. Pimentel, V. Dutra, and M. F. Madeira. 2011. Use of parasitological culture to detect Leishmania (Leishmania) chagasi in naturally infected dogs. Vector-Borne and Zoonotic Diseases 11: 1555-1560.

Alves, A. S., E. Mouta-Confort, F. B. Figueiredo, R. V. C. Oliveira, A. O. Schubach, AND M. F. Madeira. 2012. Evaluation of serological cross-reactivity between canine visceral leishmaniasis and natural infection by Trypanosoma caninum. Research in Veterinary Science 93: $1329-1333$

Barros, J. H. S., A. B. P. F. Almeida, F. B. Figueiredo, V. R. Sousa, A. Fagundes, A. G. S. Pinto, C. Baptista, and M. F. Madeira. 2012. Occurrence of Trypanosoma caninum in areas overlapping with leishmaniasis in Brazil: What is the real impact of canine leishmaniasis control? Transactions of the Royal Society of Tropical Medicine and Hygiene 106: 419-423.

Degrane, W., O. Fernandes, D. Campbell, M. Bozza, and U. G. Lopes. 1994. Use of molecular probes and PCR for detection and typing of Leishmania: A mini review. Memórias do Instituto Oswaldo Cruz 89: 463-469.

Gomes, A. H., I. M. Ferreira, M. L. Lima, E. A. Cunha, A. S. Garcia, M. F. Araújo, and V. L. Pereira-Chioccola. 2007. PCR identification of Leishmania in diagnosis and control of canine leishmaniasis. Veterinary Parasitology 144: 234-241.

Madeira, M. F., M. A. Sousa, J. H. Barros, F. B. Figueiredo, A. Fagundes, A. Schubach, C. C. De Paula, B. N. S. Faissal, T. S. Fonseca, H. K. Thoma et al. 2009. Trypanosoma caninum n. sp. (Protozoa: Kinetoplastida) isolated from intact skin of a domestic dog (Canis familiaris) captured in Rio de Janeiro, Brazil. Parasitology 136: $411-423$

Marzochi, M. C., A. Fagundes, M. V. Andrade, M. B. Souza, M. F. Madeira, E. Mouta-Confort, A. O. Schubach, and K. B. Marzochi. 2009. Visceral leishmaniasis in Rio de Janeiro, Brazil. Eco-epidemiological aspects and control. Revista da Sociedade Brasileira de Medicina Tropical 42: 570-580.

Ministério da SAÚde. 2006. Manual de Vigilância e Controle da Leishmaniose Visceral. Série A. Normas e Manuais Técnicos. Ministério da Saúde (ed), Brasilia, DF, Brasil, 120 p.

Pinto, A. G. S., T. M. Schubach, F. B. Figueiredo, C. Baptista, A. Fagundes, J. H. S. Barros, C. C. De Paula, H. K. Toma, and M. F. Madeira. 2010. Isolation of Trypanosoma caninum in domestic dogs in Rio de Janeiro, Brazil. Parasitology 137: 1653-1660.

Quaresma, P. F., S. M. Murta, E. C. Ferreira, A. C. Rocha-Lima, A. A. Xavier, and C. M. GontiJo. 2009. Molecular diagnosis of canine visceral leishmaniasis: Identification of Leishmania species by PCRRFLP and quantification of parasite DNA by real-time PCR. Acta Tropica 111: 289-294.

Silva, D. A., M. F. Madeira, A. C. Teixeira, C. M. Souza, and F. B. Figueiredo. 2011. Laboratory tests performed on Leishmania seroreactive dogs euthanized by the leishmaniasis control program. Veterinary Parasitology 179: 257-261.

Smith, A., P. Clark, S. Averis, A. J. Lymbery, A. F. Wayne, K. D Morris, AND R. C. ThOMPson. 2008. Trypanosomes in a declining species of threatened Australian marsupial, the brush-tailed bettong Bettongia penicillata (Marsupialia: Potoroidae). Parasitology 135: 1329-1335. 